\title{
Characterizations of High Early-Strength Type Shrinkage Reducing Cement and Calcium Sulfo-aluminate by Using Industrial Wastes
}

\author{
Keon-Ho Lee ${ }^{\dagger}$, Seong-Young Nam, Seung-Eui Min, Hyoung-Woo Lee, \\ Choon Han*, and Ji-Whan Ahn*** \\ Department of R\&D Team, Hanil Cement Corp., Danyang 27003, Korea \\ *Department of Chemical Engineering, Kwangwoon University, Seoul 01897, Korea \\ **Mineral Resources and Research Division, Korea Institute of Geosciences and Mineral Resources, \\ Daejeon 34132, Korea
}

(Received December 23, 2015; Revised January 29, 2016; Accepted February 25, 2016)

\begin{abstract}
In this study, the utilization of the by-products of various industries was examined using raw materials of CSA high-functional cement such as coal bottom ash, red mud, phosphate gypsum, etc. Technology to improve energy efficiency and reduce $\mathrm{CO}_{2}$ was developed as part of the manufacturing process; this technology included lower temperature sintering $\left(150 \sim 200^{\circ} \mathrm{C}\right)$ than is used in the OPC cement manufacturing process, replacement of CSA cement with the main raw material bauxite, and a determination of the optimum mix condition. In order to develop CSA cement, a manufacturing system was established in the Danyang plant of the HANIL Cement Co. Ltd., in Korea. About 4,200 tons of low purity expansion agent CSA cement (about $16 \%$ ) and about 850 tons of the lime-based expansion agent dead burned lime (about 8\%) were produced at a rate of 60 tons per hour at the HANIL Cement rotary kiln. To improve the OPC cement properties, samples of 10\%, 13\%, and $16 \%$ of CSA cement were mixed with the OPC cement and the compressive strength and length variation rate of the green cement were examined. When green cement was mixed with each ratio of CSA cement and OPC cement, the compressive strength was improved by about $30 \%$ and the expansibility of the green cement was also improved. When green cement was mixed with $16 \%$ of CSA cement, the compressive strength was excellent compared with that of OPC cement. Therefore, this study indicates the possibility of a practical use of low-cost CSA cement employing industrial wastes only.
\end{abstract}

Key words : Industrial by-products, CSA expansion admixture, Ettringite, Shrinkage-redicing, Early strength

\section{Introduction}

0 $\mathrm{n}$ the back of rapid industrialization and development, various industrial byproducts have been generated with increasing amount and thus to deal with the challenges in the area of environment and resources, it's necessary to develop the high value products using industrial byproducts selectively. Cement industry is appropriate to meet such requirements in terms of ingredient or manufacture process and the study in relevant industries has been underway. As tensile strength of concrete using ordinary Portland cement (hereinafter called OPC) is low and elastic modulus is small which cause the cracks to the concrete because of temperature stress and dry shrinkage by hydration heat in curing process. The efforts to reduce the cracks resulting from such material properties has long been underway, but unless the contractibility of cement paste itself is improved, it's impossible to fundamentally constrain dry shrinkage and shrinkage crack. To enhance the

${ }^{\dagger}$ Corresponding author: Keon-Ho Lee

E-mail : oxygen@hanil.com

Tel : +82-43-420-5660 Fax : +82-43-420-5666 contractibility of the cement paste, there's a method to compensate the contraction in a way of generating appropriate expansibility during curing and the material generating such expansion reaction includes calcium sulfo-aluminate $\left(3 \mathrm{CaO} \cdot 3 \mathrm{Al}_{2} \mathrm{O}_{3} \cdot \mathrm{CaSO}_{4}, \mathrm{C}_{4} \mathrm{~A}_{3} \overline{\mathrm{S}}^{1,2}\right)$ which is the admixture with superior properties. Calcium sulfo-aluminate (hereinafter called, CSA) which is categorized into hauyne system generates ettringite $\left(\mathrm{C}_{3} \mathrm{~A} \cdot 3 \mathrm{CaSO}_{4} \cdot 32 \mathrm{H}_{2} \mathrm{O}\right)$, monosul-fate $\left(\mathrm{C}_{3} \mathrm{~A} \cdot \mathrm{Ca}\right.$ $\left.\mathrm{SO}_{4} \cdot 12 \mathrm{H}_{2} \mathrm{O}\right)$ and calcium hydroxide $\left(\mathrm{Ca}(\mathrm{OH})_{2}\right)$ in needle shape or pillar shape when mixed with cement and water that generates hydration reaction expands cement concrete and fills micropores that makes possible shrinkage-compensation concrete as well as quick-setting by adjusting the generation of ettringite. ${ }^{3,4)}$

In this study, CSA clinker could be produced on cement kiln for commercial production by selecting the industrial byproduct which is favorable in components and properties as well as reducing the material to be mixed and production was made at burning temperature $1,200 \sim 1,300^{\circ} \mathrm{C}$ which is relatively lower than synthetic temperature of OPC clinker. With CSA clinker produced, properties as CSA cement were examined at various conditions with the content of plaster and physical properties as the high early-strength shrink- 
age-reducing cement were examined by substituting-adding to $\mathrm{OPC}$ at certain ratio.

\subsection{Theoretic background}

1.1.1 Hydration reaction mechanism of expanding admixture.

In hydration reaction mechanism of CSA expanding admixture, calcium hydroxide crystal is generated by hydration reaction of free lime as Fig. 1 and contributes to expansion. But calcium hydroxide forms solid solution with aluminate lime as a result of reaction with hauyne and is reduced. Then it generates needle-shaped crystal, called ettringite as a result of reaction with anhydrite which will cause the expansion. Expansion force generated by needleshaped ettringite contributes effectively to improve dry shrinkage of cement concrete and to make it not to deteriorate the durability, it's more important to make the balance in timing between cement hydration and curing and expansion. $^{5-7)}$

\subsubsection{Characteristics and use of CSA}

CSA has early strength when containing more $\mathrm{Al}_{2} \mathrm{O}_{3}$ in combining $\mathrm{CaSO}_{4}$ and $\mathrm{CaO}$ and high strength when containing more $\mathrm{SO}_{3}$ and expansibility when containing more $\mathrm{CaO}$ which thus need to be adjusted properly depending on intended use. Fig. 2 shows the characteristics of the content of components depending on combination of three components of $\mathrm{CaO}-\mathrm{Al}_{2} \mathrm{O}_{3}-\mathrm{SO}_{3}$ system Table 1 indicates the characteristics and use of special binder in CSA system.

\section{Experimental Procedure}

\subsection{Starting material}

As $\mathrm{Al}_{2} \mathrm{O}_{3}$ source, bottom ash and sludge generated from thermal power generation and as $\mathrm{SO}_{3}$ source, phosphoric acid byproduct plaster and as $\mathrm{CaO}$ source, limestone used

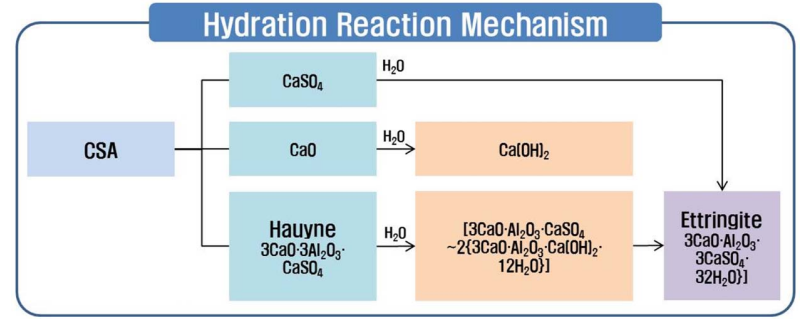

Fig. 1. Hydration reaction mechanism of CSA expansion admixture.

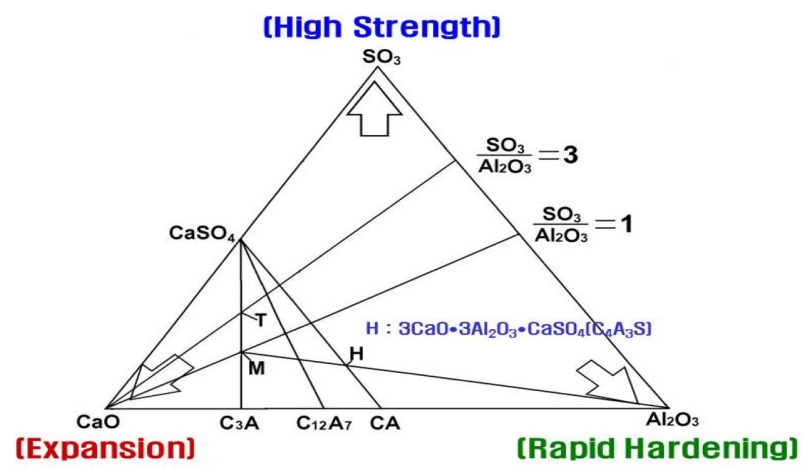

Fig. 2. Relation between chemical composition and properties of additives in the system $\mathrm{CaO}-\mathrm{Al}_{2} \mathrm{O}_{3}-\mathrm{SO}_{3}$.

for category 1 OPC manufacture and lime industry were used.

CSA clinker was made by mixing the materials at the ratio, $\mathrm{CaO}: \mathrm{Al}_{2} \mathrm{O}_{3}: \mathrm{CaSO}_{4}=3: 3: 1$ and synthesizing in Lab. scale electric furnace at various temperature range, $1,000 \sim 1,400^{\circ} \mathrm{C}$ and mass production was made with the specimens satisfying the requirements as CSA clinker at pilot plant and in production kiln. Table 2 shows chemical components of materials used.

Table 1. CSA System Characteristics and Use of Special Binders

\begin{tabular}{lll}
\hline & \multicolumn{1}{c}{ CSA System Characteristics } & Use of Special Binders \\
\hline \multirow{2}{*}{ Expansion } & - Combination of Water in Hydration & - Antiwashout Underwater Cement \\
& - Formation of Ettringite & - Heat Resistance Chemical PC Product \\
& - Shrink-reduced of Hardness & - Microcement \\
High Early & - To Promote the Initial Hydration & - Ultra Rapid Hardening Cement \\
Strength and & - Available in Cementation & - Waterproof Coating \\
Water Resistance & - Block Porosity by Ettringite & - Selfleveling \\
& - Increase of High Strength and Water Resistance & - High Strength Cement \\
Chemical & - Increased Reactivity of the Chemicals & - Grout High Early Strength Cement \\
Resistance & - Increase of the Chemical Resistance by $\mathrm{C}_{3} \mathrm{~A}$ Consumption & - Emergency Repair Concrete \\
\end{tabular}

Table 2. Chemical Composition of Raw Materials

\begin{tabular}{|c|c|c|c|c|c|c|}
\hline \multirow{2}{*}{ Type } & \multicolumn{6}{|c|}{ Chemical Compositions(\%) } \\
\hline & $\mathrm{SiO}_{2}$ & $\mathrm{Al}_{2} \mathrm{O}_{3}$ & $\mathrm{Fe}_{2} \mathrm{O}_{3}$ & $\mathrm{CaO}$ & $\mathrm{SO}_{3}$ & $\mathrm{MgO}$ \\
\hline Lime Stone & 9.93 & 1.68 & 0.65 & 45.49 & 0.01 & 2.73 \\
\hline Bottom Ash & 53.04 & 28.18 & 7.09 & 1.23 & 0.24 & 0.58 \\
\hline Gypsum & 0.96 & 1.24 & 0.16 & 31.92 & 38.21 & 1.21 \\
\hline
\end{tabular}



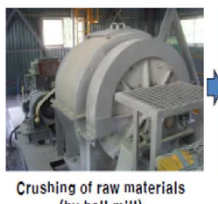

(by ball mill)

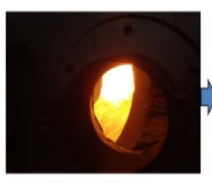

Kiln heating up

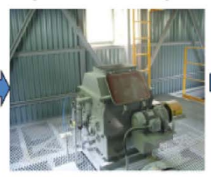

Mixture of raw materials (by mixer)

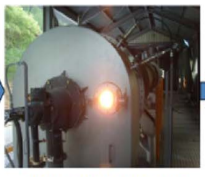

The operation of the kiln

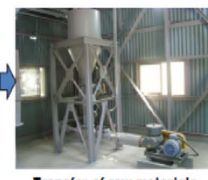
Transfer of raw materials
(by blower)

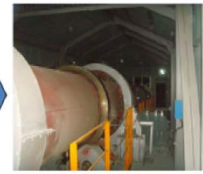

The operation of the kiln

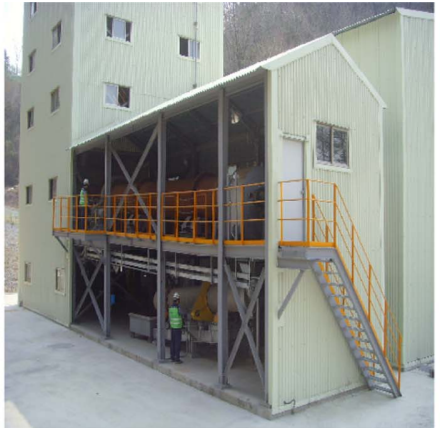

Fig. 3. Green cement pilot plant.
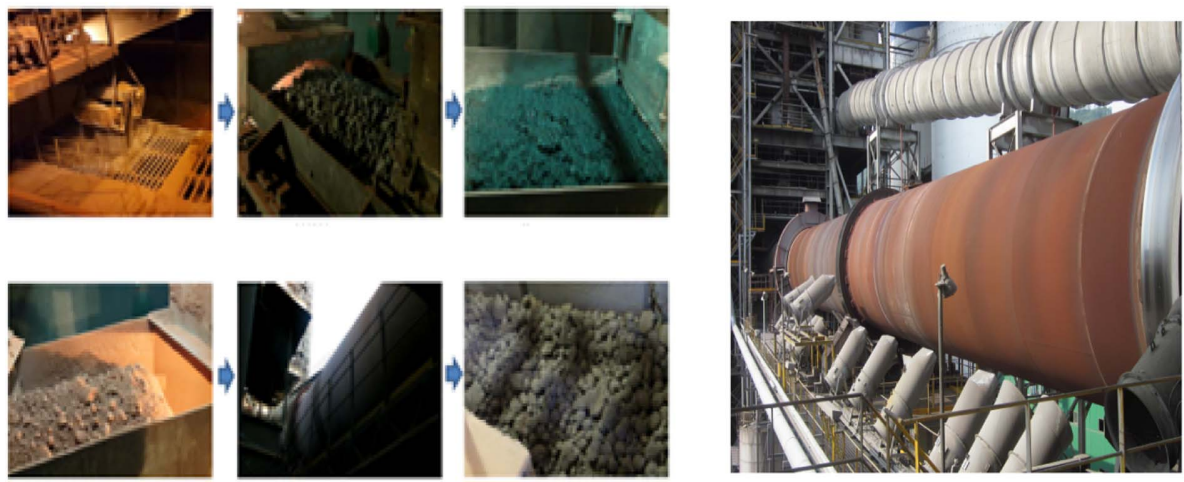

Fig. 4. Cement manufacturing process and kiln.

\subsection{Production of CSA clinker}

Specimen of CSA clinker was produced at pilot plant where plasticity conditions by process (temperature of preheating tower, pressure, material balance, heat balance) can be monitored (Fig. 3) and based on process technologies obtained from pilot plant, test production of CSA clinker started on cement kiln for commercial production as Fig. 4 (1,700 ton/day, 300,000 ton/year)

\section{Results and Discussion}

Physical properties of CSA expansive admixture was reviewed after mixing a certain portion of desulfurized plaster with CSA clinker produced in production kiln.

\subsection{Setting time}

Setting of CSA expansive admixture was measured vicat device according to KS L 5108. As shown in Fig. 5, initial setting time of category $1 \mathrm{OPC}$ was $5 \mathrm{~h}$ and final setting time was $6 \mathrm{~h} 25 \mathrm{~min}$ while initial setting time of CSA expansive admixture was $14 \mathrm{~min}$ and final setting was $29 \mathrm{~min}$, which are much faster than category 1 OPC, demonstrating a quick setting performance.

\subsection{Change in length}

To check early plasticity/dry shrinkage of CSA expansive agent, one meter length change test device was used and the result is as Fig. 6 . While category 1 OPC tends to contract in proportion to aging, CSA expansive agent indicated

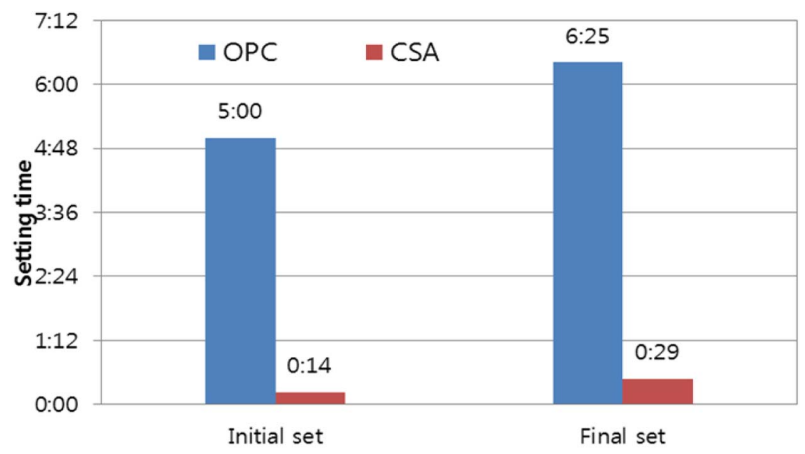

Fig. 5. Results of setting time.

expansibility from the early stage of hydration by generating ettringite. Expansion rate increased rapidly more than category 1 OPC, indicating $280 \%$ of expansion rate in maximum.

\subsection{Minor hydration heat}

Temperature stress is the factor that should not be ignored in concrete crack. More cracks occur in structure with thin section while the cracks in thick structure occur when temperature after rising by hydration heat falls. CSA expansive agent generates minor hydration heat that doubles the category 1 OPC by generating ettringite immediately after injection, but reaction time was maintained for $12 \mathrm{~h}$ which was then $1 / 3$ of the value of Chinese-made CSA expansive agent in market (Fig. 7) 


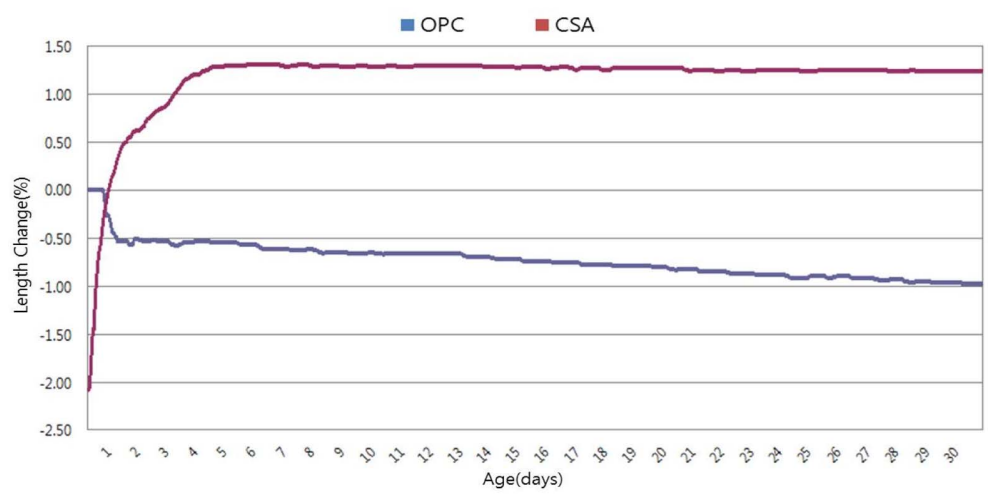

Fig. 6. Results of $1 \mathrm{~m}$ shrink reduction.
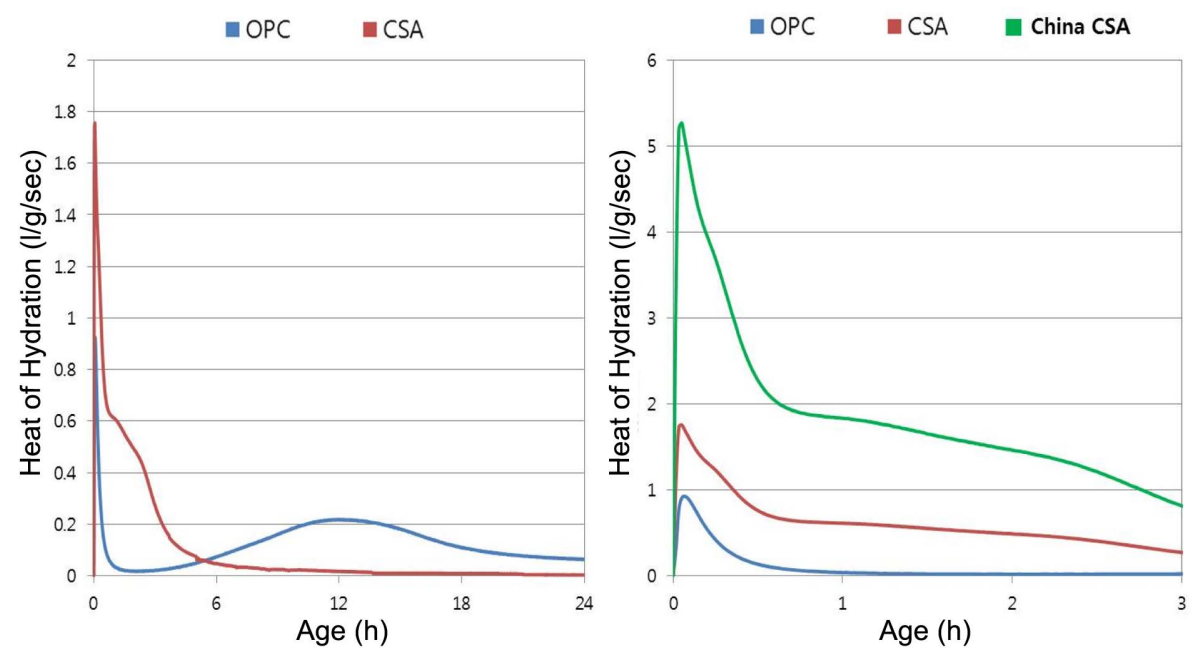

Fig. 7. Results of hydration heat.

\subsection{Hydration product}

Hydration product at early stage of CSA expansive agent was analyzed using a scanning electron microscope (sem) and Fig. 8 shows the hydration product in $1 \mathrm{~h}$ and $12 \mathrm{~h}$. It's confirmed that CSA expansive formed hydration product in hexagonal pillar-shaped that is influential on expansion force and thus dry shrinkage and shrinkage crack in cement concrete is expected to be improved by forming ettringite on voids in hardened body.

\subsection{Characteristics of early strength shrinkage- reducing cement product}

Early strength and shrinkage reduction of category 1 OPC were achieved using CSA expansive agent and physical properties of early strength shrinkage-reducing cement such as minor hydration heat, setting time, fluidity, changes in length, density and compressive strength were examined.

\subsubsection{Minor hydration heat}

Minor hydration heat of early strength shrinkage-reducing cement measured is as Fig. 9. On the contrary to CSA expansive agent, early hydration heat of early strength shrinkage-reducing cement was similar to category 1 OPC and was slightly increased in $5 \mathrm{~h}$ till $17 \mathrm{~h}$.

\subsubsection{Setting time and fluidity}

Early workability of cement concrete mixed with CSA expansive agent is the critical factor to determine the quality of the product. Fig. 10 shows setting time and fluidity of early strength shrinkage-reducing cement, which indicated setting time earlier than category 1 OPC by 50 minutes by generating ettringite hydrate as much as CSA expansive agent substituted and fluidity, though slightly low in change over time $(1 \mathrm{~h})$ had similar properties.

\subsubsection{Change in length}

Change in length of early strength shrinkage-reducing cement depending on curing condition was examined using contact gauge micrometer method and $1 \mathrm{~m}$ length change tester in a bid to maximize the hydration reaction (Fig. 11) When testing using contact gauge, early strength shrinkage-reducing cement was expanded about $80 \%$ of category 1 OPC at early hydration stage and shrinkage reduction by about $25 \%$ at late hydration stage. And when it comes to the change in length at air-dried state, shrinkage reduction by 

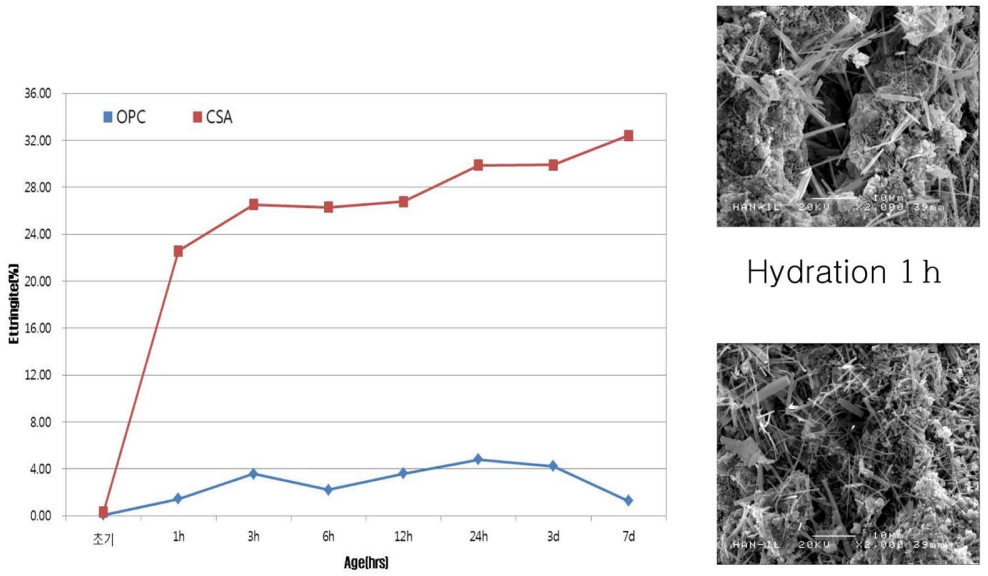

Hydration $1 \mathrm{~h}$

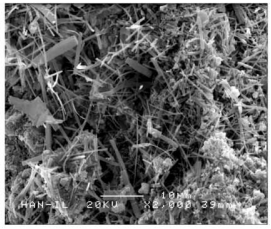

Hydration $12 \mathrm{~h}$

Fig. 8. SEM microphotographs of hardened paste prepared with CSA expansive.
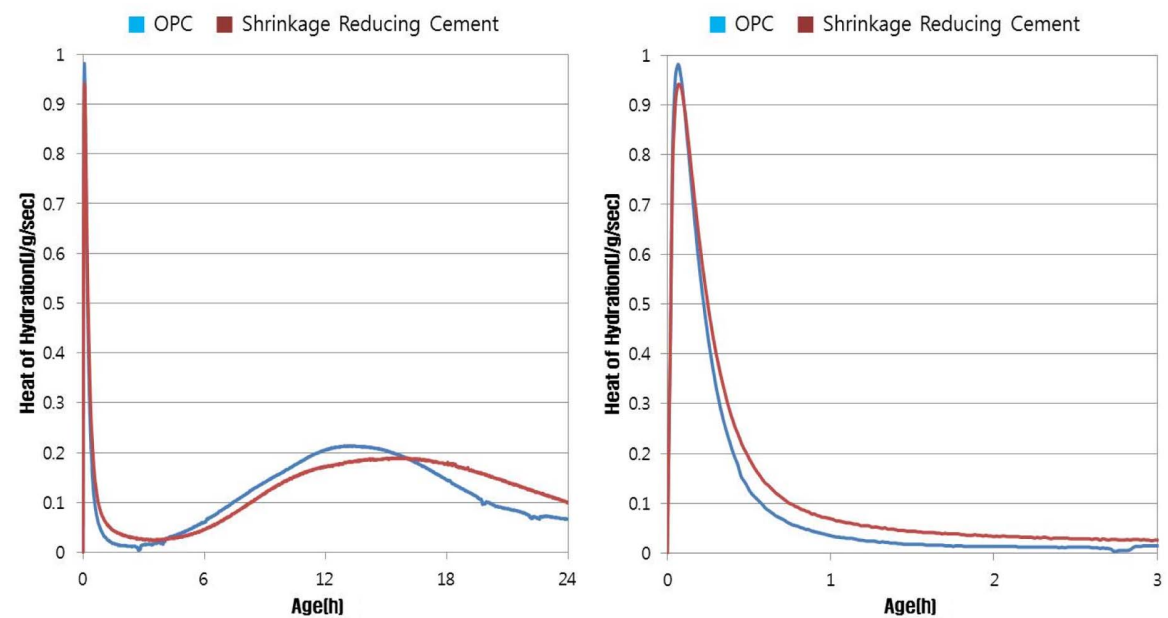

Fig. 9. Results of hydration heat.
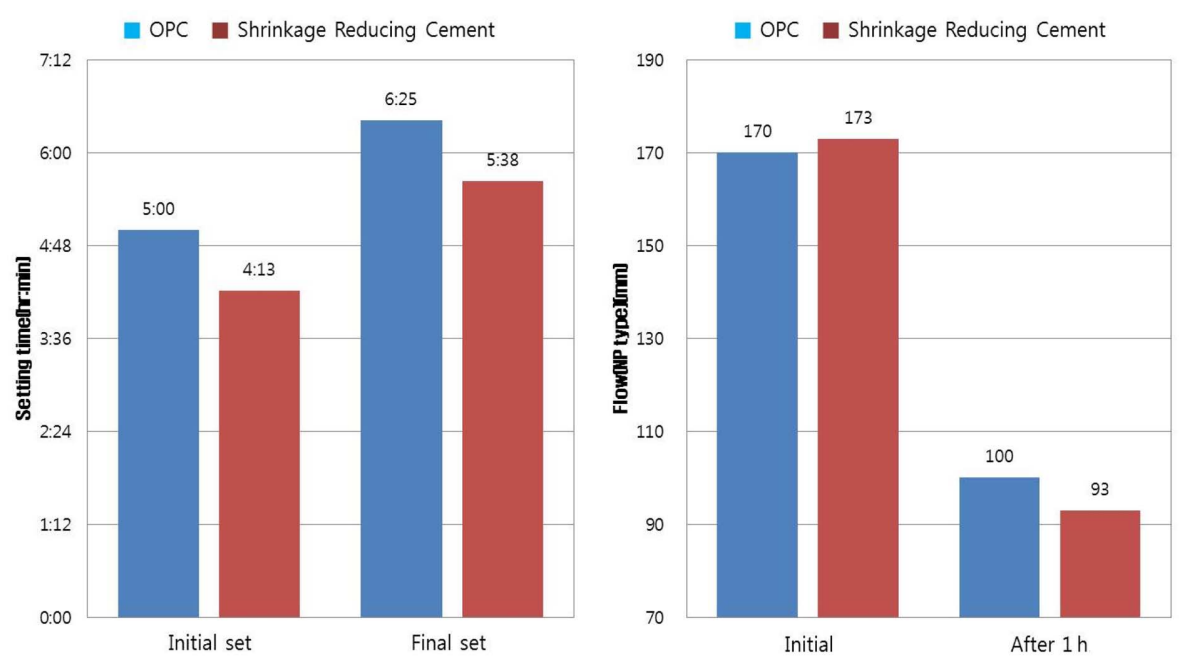

Fig. 10. Results of setting time and flow. 

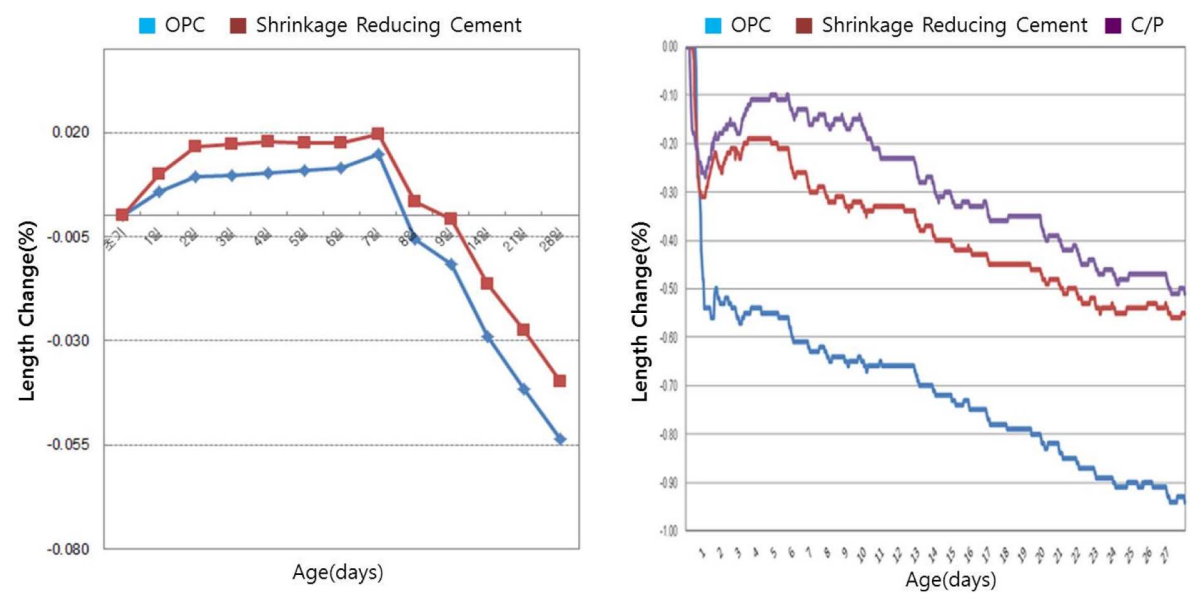

Fig. 11. Results of $1 \mathrm{~m}$ shrink reduction.
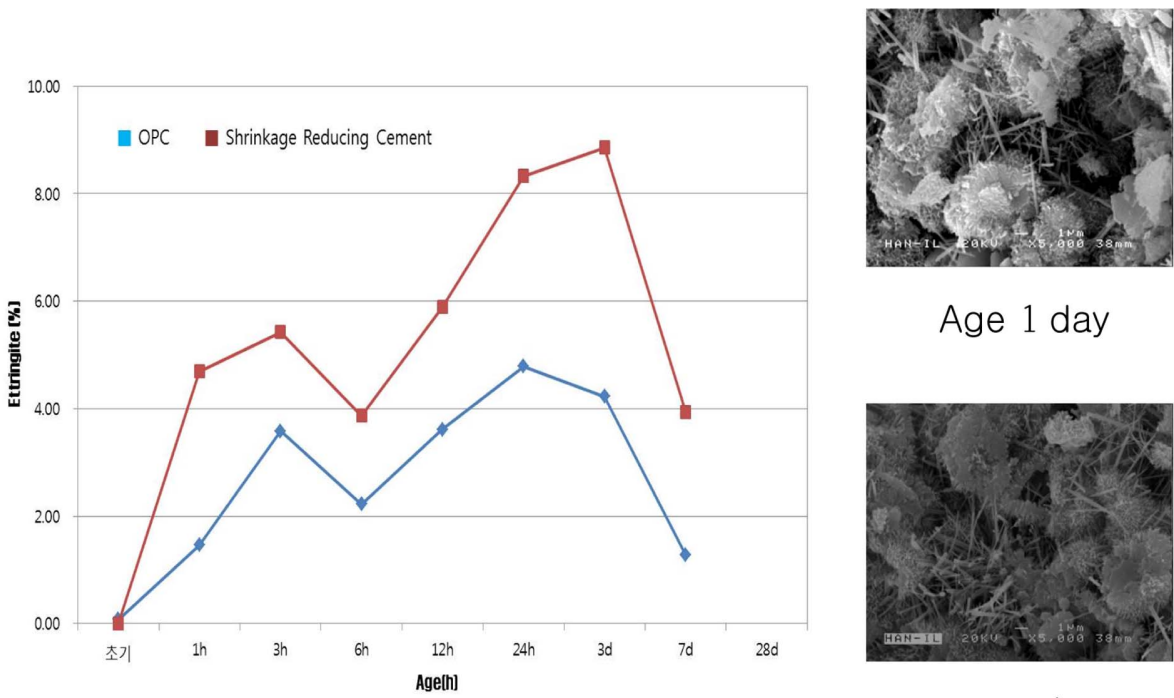

Age 1 day

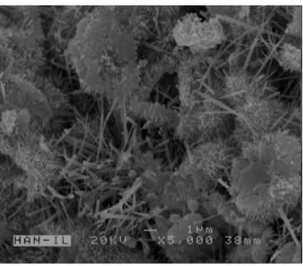

Age 3 days

Fig. 12. SEM microphotographs of hardened paste prepared with CSA expansive.

about $40 \%$ comparing to category 1 OPC was confirmed, which indicated that early strength shrinkage-reducing cement mixed with CSA expansive agent filled the voids on hardened body in proportion to growth pressure of ettringite hydrate crystal that brought about shrinkage reduction effect.

\subsubsection{Hydration product}

Figure 12 shows the graph comparing hydration products by material age of early strength shrinkage-reducing cement with the photo. Comparing to category 1 OPC of which main hydration product is calcium hydroxide, early strength shrinkage-reducing cement generated ettringite $320 \%$ more than category 1 OPC (x-ray diffraction quantitative analysis) and according to observing microstructure, generation of ettringite on the third day was increased from the first day.
3.5.5 Compressive strength and density

As indicated by the test result, compressive strength of early strength shrinkage-reducing cement at early stage, the first day, was increased by $18 \%$ comparing to category 1 OPC but was similar at late stage in 28 days. According to the density over time, early strength shrinkage-reducing cement had more dense structure than category 1 OPC because the voids on hardened body were filled with ettringite hydrate (Fig. 13)

\section{Conclusions}

CSA expansive agent is produced on cement kiln for commercial production by using industrial byproduct selectively and early strength shrinkage-reducing cement is produced and as a result of analyzing the physical properties of this cement, following conclusion was made.

(1) CSA clinker which is the main material of shrinkage- 

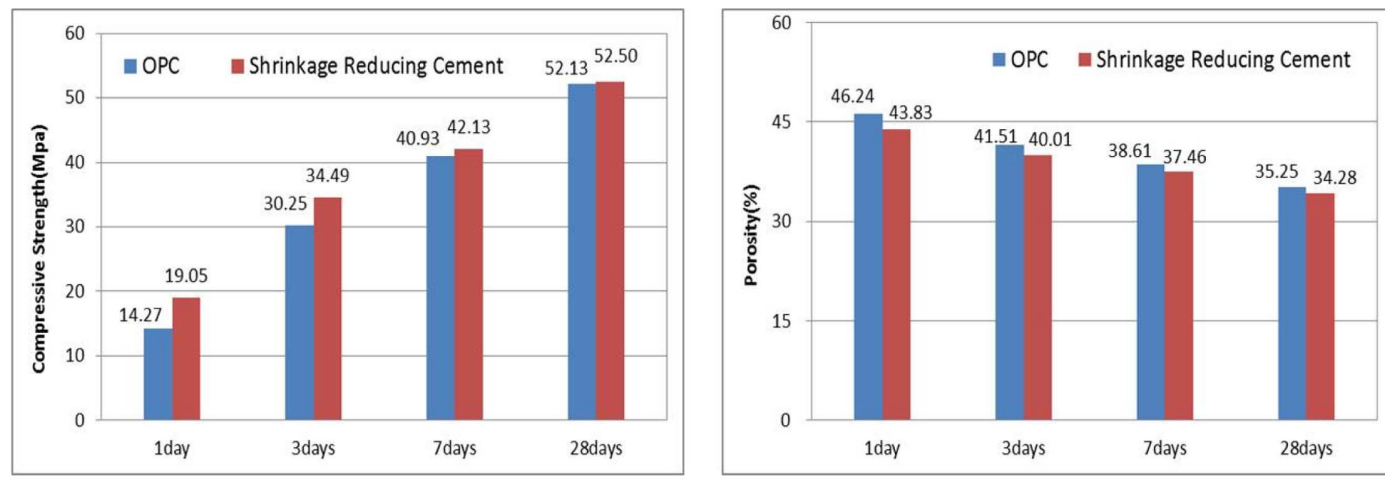

Fig. 13. Results of compressive strength and porosity.

reducing material could be produced at $1,200 \sim 1,300^{\circ} \mathrm{C}$ which is lower than synthetic temperature of category 1 OPC clinker.

(2) Furthermore, technology that will minimize the quality deviation through real-time monitoring as well as mass production system with the system compatible with category 1 OPC were developed and secured.

(3) CSA expansive agent generated ettringite hydrate in hexagonal pillar-shaped which improved dry shrinkage and shrinkage crack in cement concrete by filling the voids on hardened body.

(4) Early strength shrinkage-reducing cement using CSA expansive agent indicated increased early compressive strength from category 1 OPC with superior durability without deteriorating the quality which is expected to make commitment to developing the structure at low cost with a long-term service life by improving shrinkage.

\section{Acknowledgments}

This research was supported by a grant (2013) from the Energy Technology Development Program (2013T10010 0021), funded by the Ministry of Trade, Industry and
Energy of the Korean government.

\section{REFERENCES}

1. Yasuo Arai, Cement Materials Chemistry (Second edition); Dainippon Tosho Publishing Co., Ltd., 1990.

2. G. M. George, "Industrial Aluminous Cement; pp. 415-470, Applied Science Publishers Ltd, London, 1983.

3. O. Andac and F. P. Glasser, "Polymorphism of Calcium Sulfoaluminate and its Solid Solution," Adv. Cem. Res., 22 [6] 57-60 (1994).

4. D. Min and T. Mingshu, "Formation and Expansion of Ettringite Crystals," Cem. Concr. Res., 24 [1] 119-26 (1994).

5. E. Sakaiand and M. Daimon, "Morpology and Formation of Calcium Aluminate Hydrates," Inorg. Mater., 258 [2] 37582 (1995).

6. N. J. Calos, C. H. L. Kennard, A. K. Whittaker, and R. L. Davis, "Structure of Calcium Aluminate Sulfate $\mathrm{Ca}_{4} \mathrm{Al}_{6} \mathrm{O}_{16} \mathrm{~S}$," J. Solid State Chem., 119 [1] 1-7 (1995).

7. K. Okawa and D. M. Roy, "C4A3S Hydration, Ettringite Formation, and its Expansion Mechanism: II. Microstructural Observation of Expansion," Cem. Conc. Res., 12 [1] 101-9 (1982). 